\title{
OPERATION OF TWO-SHAFT GAS TURBINE IN THE RANGE OF OPEN ANTI-SURGE VALVE
}

\author{
Marek Dzida \\ Jacek Frost \\ Gdańsk University of Technology, Faculty of Ocean Engineering and Ship Technology, Poland
}

\begin{abstract}
This paper presents experimental tests of full-scale two-shaft gas turbine in the range of open anti-surge valve (ASV). The tests were carried out in a laboratory gas- turbine test stand belonging to Department of Automation and Power Engineering, Faculty of Ocean Engineering and Ship Technology, Gdańsk University of Technology. The tests covered the start-up and low load operation of the turbine set in the range of open anti-surge valve.
\end{abstract}

Keywords: gas turbine, anti-surge valve, laboratory stand, experimental studies

\section{INTRODUCTION}

Power plants based on gas turbines are applied into many driving devices : in power industry - for driving electric generating sets working in simple or combined gas-steam systems, in aeronautics - gas turbine serves as a basic engine, in military applications, especially in shipbuilding, in ocean engineering as well as in intermediate pumping stations of piping networks for transporting gas or crude oil products etc. They are used in a micro-scale beginning from a few hundred watts, up to several hundred megawatts available from a single driving engine. Main aspects of application of gas turbines are the following : low values of ratio of their mass and volume to unit of power output, high easiness of application of automation, possible fast start-ups and cyclicmode operation, low or full independence from cooling water, possible freedom in selecting location place within the engine room, especially in power generation applications, low failure frequency, low emission of contaminations, especially $\mathrm{NO}_{x}$ and sulphur compounds, to the atmosphere.
Gas turbine plants can operate in a broad range of load changes, hence in diagnostics of such engines much attention is placed to the issues of partial loads. For gas turbines partial loads are more important than for steam power plants as in the steam turbines change of power is achieved mainly by changing dose of working medium, i.e. water steam, whereas the remaining parameters of the medium at inlet to turbine are rather invariable. In gas turbines a change in their power output is accompanied with broad changes in all cycle parameters and engine efficiency. Calculation of operational parameters of gas turbine under partial loads either in steady conditions ( static characteristics) or transient ones ( dynamic characteristics ) becomes a difficult and very complex task.

Especially difficult case of gas turbine operation is its work in the range of open anti-surge valve. The gas turbine operation in the range of open anti-surge valve (ASV) occurs at a low load from the side of consumer as well as during starting-up and stopping the turbine. This is the range of turbine operation in which anti-surge valve is automatically(i.e. without any interference of operator ) activated to cause increasing air flow 
rate from rotary compressor in order to shift its working point off the unstable work area into stable work one. An air surplus behind the compressor is discharged to the atmosphere, Fig. 1.

In the range of open ASV, gas turbine characteristics, especially gas turbine cycle efficiency, are radically changed. The efficiency drops fast and the gas turbine as a rule should not operate at all in this range. The work with open ASV occurs rather rarely and results from the reasons for safe operation of turbine set $[2,3]$.

In the subject-matter literature there are only scarce publications concerning gas turbine operation in the range of open anti-surge valve [5]. This paper covers issues dealing with the problem and describes experimental tests performed on the test stand including full-scale gas turbine.

\section{TWO-SHAFT GAS TURBINE}

For aircraft drives, application is usually made of the twoshaft system in which a separate part of turbine is devoted to drive compressor only, Fig.1.

The unit consisted of a compressor, combustion chamber and compressor turbine serves as a gas generator. Its aim is to produce hot gas of the parameters $\left(p_{3} t_{3}\right)$, which, expanding in the compressor turbine, transforms a part of its thermal energy into mechanical one. The role of the gas generator is similar to that of a steam boiler with supply pump in a steam turbine power plant. Further expansion occurs in a power turbine which delivers its output to a consumer. In the above described system the air (working medium) is absorbed from the atmosphere and sent back to the atmosphere in the form of exhaust gase therefore such cycles are called open cycles. The cycles are usually used in gas turbines driving mechanical devices including those in ship power plants.

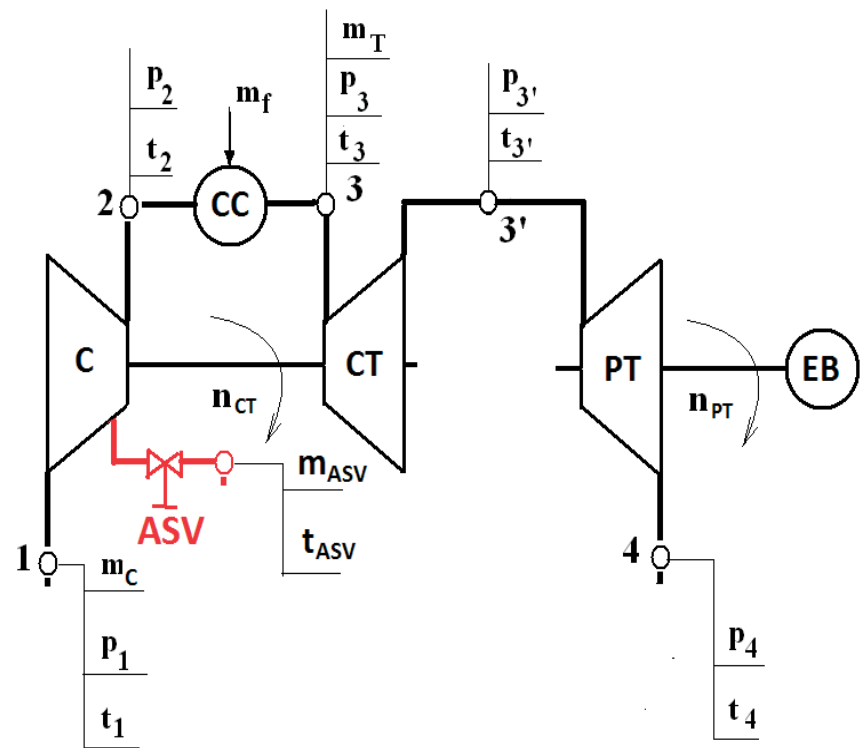

Fig. 1. Schematic diagram of two-shaft gas turbine. Simple open cycle (see Designations)

\section{OPERATION OF TWO-SHAFT GAS TURBINE IN THE RANGE OF OPEN ANTI- SURGE VALVE}

A two-shaft gas turbine installed on the engine test bed of the Department of Automation and Power Engineering, Faculty of Ocean Engineering and Ship Technology, Gdańsk University of Technology, was used for the tests. The gas turbine is of a light-aircraft type; it is applicable to driving the helicopter and operates according to simple cycle ( Fig. 1) [1].

The gas turbine is consisted of (see Fig. 1):

- the compressor (C) of seven axial stages and one radial stage,

- the combustion chamber (CC) consisted of the body with collecting scroll and air pipes, flame tube, working injector and flame igniter,

- the compressor turbine (CT) - axial, one-stage,

- the power turbine (PT) - axial, two-stage,

- the eddy-current brake (EB) directly coupled with the turbine's shaft.

Nominal parameters of the turbine in ISO conditions are the following [4]:

- the power $\mathrm{Ne}=235 \mathrm{~kW}$

- the compressor turbine shaft rotational speed $\mathrm{n}_{\mathrm{CT}}=90 \%$ (39375 rpm)

- the power turbine shaft rotational speed $n_{\mathrm{PT}}=101 \%(24240$ rpm)

- the exhaust gas temperature behind the combustion chamber, $\mathrm{t}_{3}=870^{\circ} \mathrm{C}$

- the fuel flow rate $\mathrm{m}_{\mathrm{f}}=0,0808 \mathrm{~kg} / \mathrm{s}$

In order to assure a required static operation reserve for the compressor in all gas turbine operation ranges, an antisurge valve which releases air flow from behind $6^{\text {th }}$ stage of the compressor, was applied. The engine operates with open anti-surge valve during start-up and idle run down till a determined low rotational speed of compressor turbine, $\mathrm{n}_{\mathrm{CT}}$. Fig. 2.1 presents the range of compressor turbine rotational speed in function of atmospheric conditions (air temperature), which causes the shutting- up of the anti-surge valve [4].

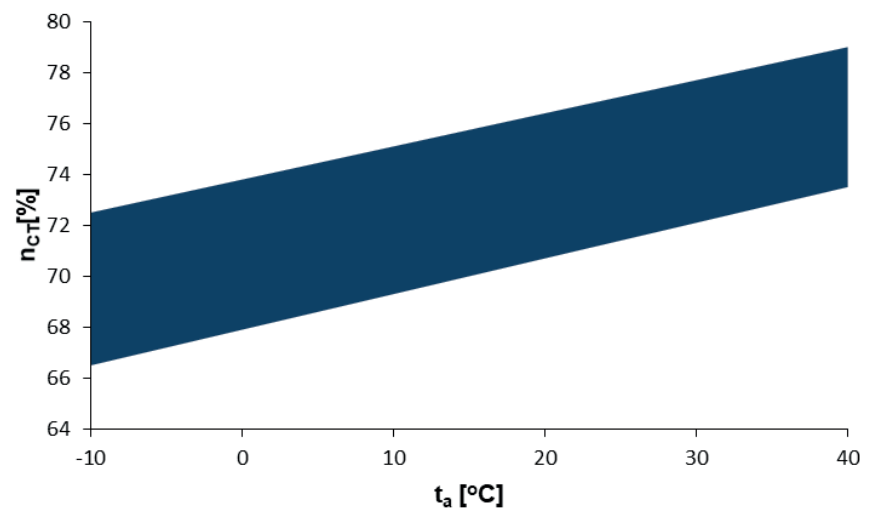

Fig. 2.1. The range of compressor turbine rotational speed in function of atmospheric conditions (air temperature) in which the anti-surge valve is shut up (acc. producer's data [4]) 
In the presented engine control of air extraction is executed by means of an automatic air extraction controller which starts the hydraulic valve to extract air from behind $6^{\text {th }}$ compressor stage, Fig. 2.2.

To the stub pipe " $\mathrm{A}$ " the air pressure $\mathrm{p}_{2}$, is applied from behind the compressor; the pressure is reduced by inlet and outlet nozzles placed in the pump controller of the fuel control system of the engine. To the stub pipe „B” the total air pressure $\mathrm{p}_{2}$ is applied from behind the rotary compressor.

To the stub pipe " $C$ " fuel is supplied under high pressure from the pump controller, and from the stub pipe „E” control pressure is sent into the mechanism actuating air extraction valve.

As long as the engine turbocompressor does not yet reach the rotational speed determined from Fig. 2.1, the slider "S” remains in its upper point. When the demanded pressure ratio $\mathrm{p}_{2}, / \mathrm{p}_{2}$ is obtained, the slider "S" is displaced down. In this position the lower edge of the slider opens fuel flow under high pressure into the stub pipe " $E$ "; the pressure controls the anti-surge valve switching-on. The air - extraction valve is now closed. Operation of the air - extraction valve is controlled by the air - extraction automatic controller where the poppet valve connected with the piston is made open due to high pressure of the fuel delivered through the stub pipe „E” connected with the working space of the piston and the air-extraction automatic controller. The stub pipe " $\mathrm{D}$ " is connected with the discharge stub pipe of the pump contoller.
Photo 1 shows location of the anti-surge valve within the gas turbine.

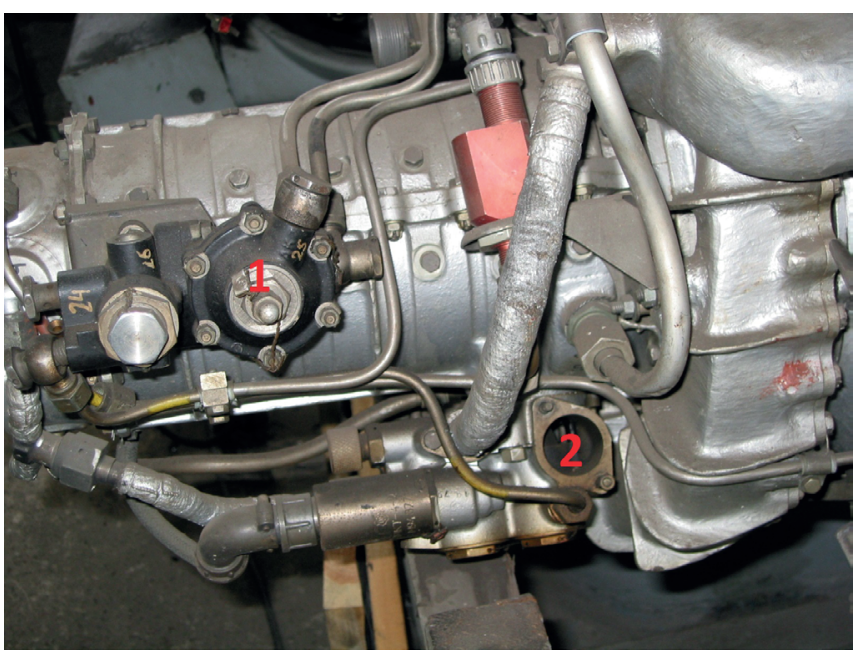

Photo 1. Air extraction from behind 6th stage of the compressor 1. Air-extraction automatic controller; 2. Anti-surge valve.

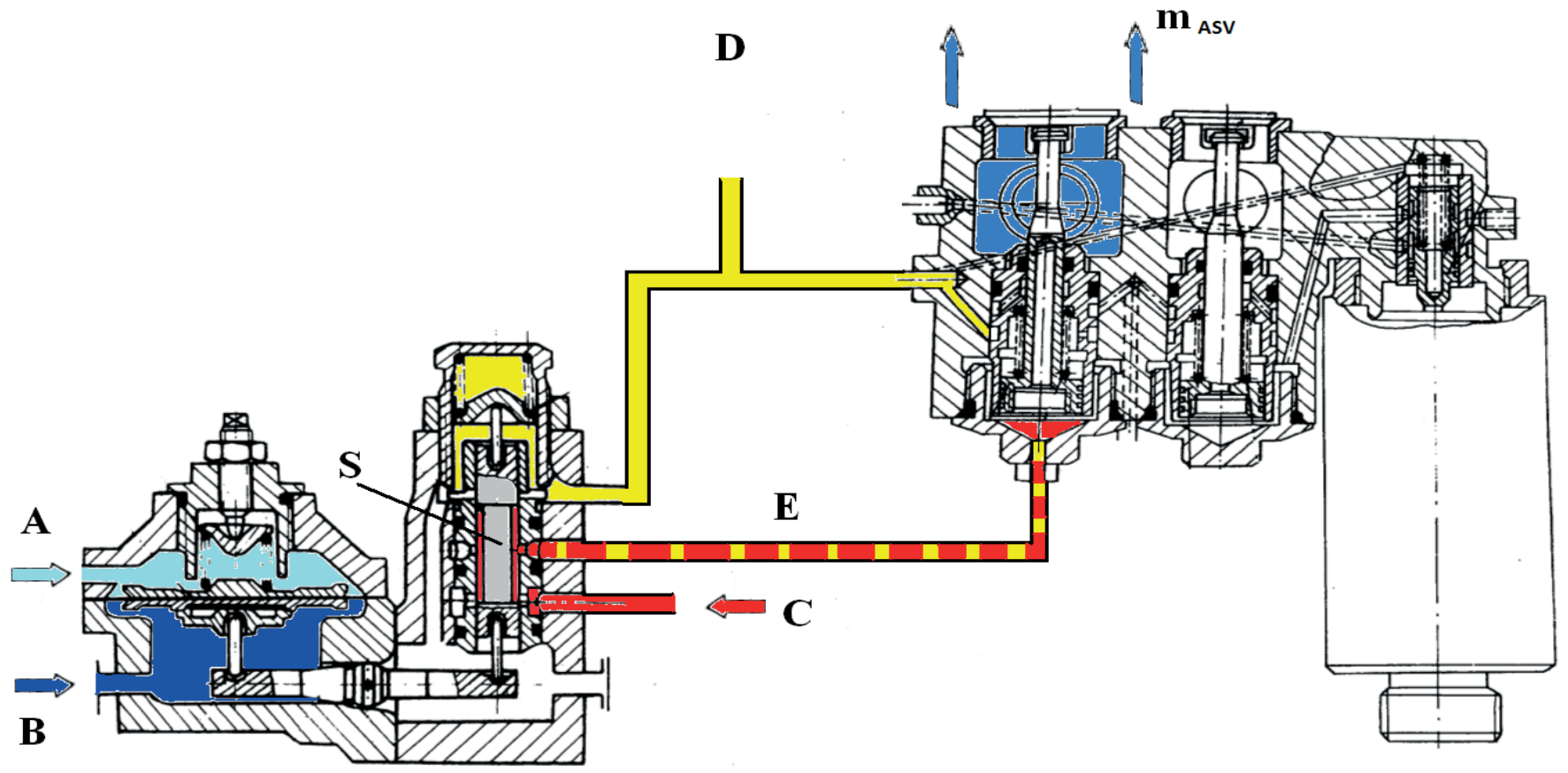

Fig. 2.2. Schematic diagram of the air-extraction control system [4]A - the air pressure $p_{2} ; B$ - the air pressure from behind the compressor, $p 2 ; C$ - fuel high pressure from the pump controller; $D$ - discharge stub pipe; E- the crossover between the air-extraction control device and air-extraction valve; S- slider; $m_{A S V}$-extraction air flow rate.

\section{MEASUREMENT STAND [1]}

The gas turbine measurement stand is shown in Photo 2. The stand was equipped with control and measurement systems as well as auxiliary devices including eddy-current brake, control and measurement software as well as data 
recording and visualization software delivered by ODIUT Automex Co. Ltd ${ }^{1}$. The stand contains also the gas turbine engine $^{2}$ coupled with the eddy-current brake. The engine absorbs air from outside of the building through the suction pipe fitted with a filter at its end ; exhaust gas from PT is directed to the atmosphere through an outlet funnel combined with a silencer. The eddy-current brake is cooled with water flowing in a closed system.

The turbine is controlled from an acoustically insulated cabin. The engine may be loaded by acting upon fuel system with the use of the gas charge lever or by loading the eddycurrent brake, directly. The setting of the gas lever and of the brake may be changed simultaneously by using electronic contol.

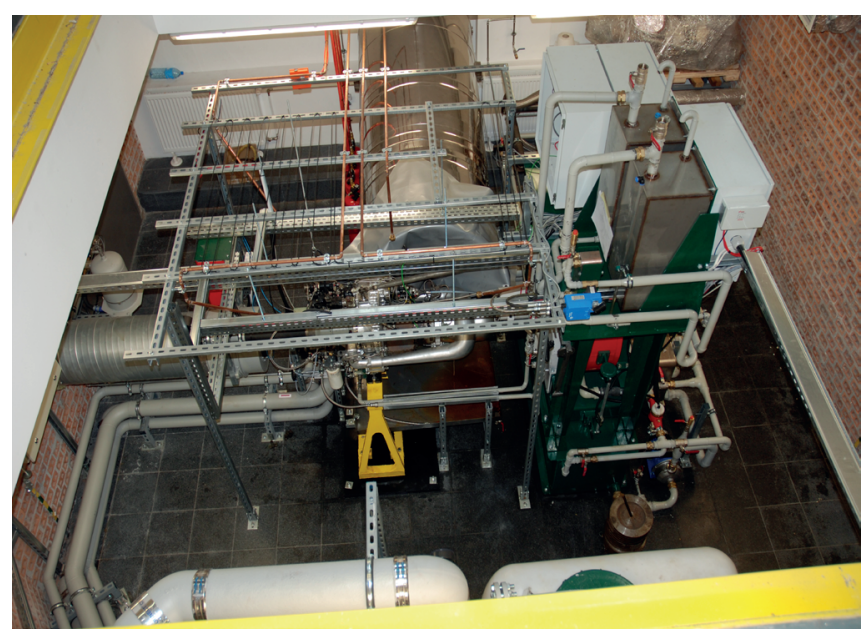

Photo 2. The test and didactic stand containing the two-shaft gas trbine

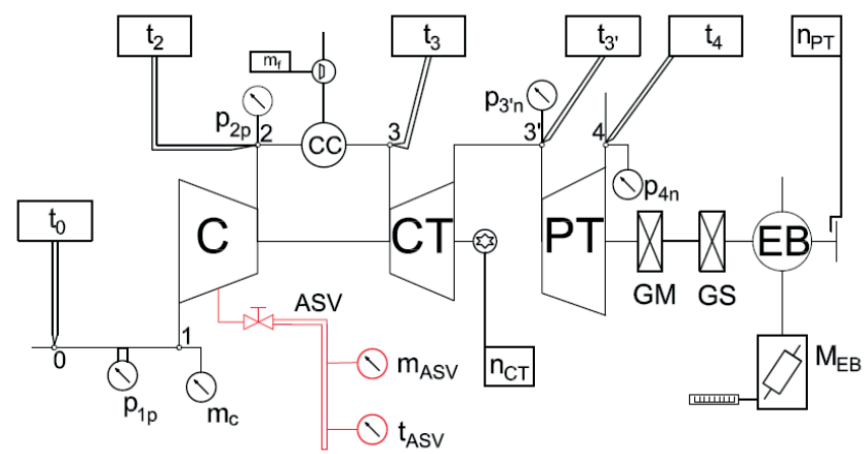

Fig. 3. Schematic diagram of the measurement system of the gas turbine test stand with possible measurement of the extraction air parameters [1]

The engine is controlled from the control cabin by means of digital controllers ( controlling module) connected together by CAN bus which makes it possible to control simultaneously the two-dimension object : the gas turbine and eddy-current brake as well as the measurement module, by means of a computer system.

ODIUT Automex sp. z o.o. (Ltd) designed and equipped the turbine station. All screenshots come from the company's own design.

The GTD-350 turbine engine in the property of the Gdańsk University of Technology was modernised and prepared for the tests in accordance with the instructions of the Department of Automatics and Turbine Propulsion by WSK “PZL-Rzeszów” S.A
The engine was specially adjusted to experimental tests by introducing additional measurement points to the standard engine instrumentation.

Fig. 3 presents the measurement scheme of the gas turbine test stand. To make it possible to measure parameters of air extraction from the rotary compressor, an additional measurement line allowing to determine the parameters was adjoined to the existing measurement system. In Fig. 3 additional measurement channels are distinguished by bold lines. In the outlet from the anti-surge valve a pipe for discharging air to the atmosphere was installed. On the pipe a sensor for measuring the extraction air flow rate $\mathrm{m}_{\mathrm{ASV}}$ and its temperature $t_{A S V}$, was attached (Sensor of Non-Incendive Type 4X, Model: ST50-AG12B000), Photo 3.

The test stand allows to measure not only static characteristics but also dynaminc ones with a short time of signal samping.

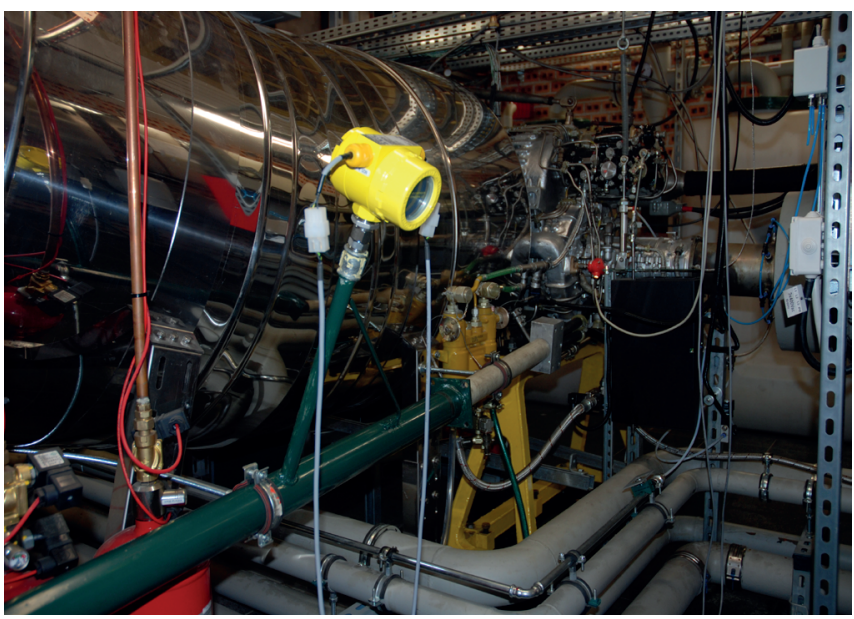

Photo. 3. Measurement of extraction air parameters on the gas turbine test stand

\section{EXPERIMENTAL TESTS OF GAS TURBINE PARAMETERS IN THE RANGE OF OPEN ANTI-SURGE VALVE}

During start up of the turbine set as well as under low loads the gas turbine operates with open anti-surge valve which assurs stable operation of the turbine set. The tests in question are aimed at the measuring of gas turbine parameters, especially air flow rate from anti-surge extraction point. The usual instrumentation of the gas turbine test stand makes it possible to measure only the air flow rate at the inlet to the turbine set, $\mathrm{m}_{\mathrm{C}}$, Fig. 3, because of the air inlet. location place. At the open anti-surge valve, the air flow rate to the combustion chamber, $\mathrm{m}_{2}$ is not known.

The air flow rate $m_{2}$ delivered to the combustion chamber results from th relation:

$$
\mathrm{m}_{2}=\mathrm{m}_{\mathrm{C}}-\mathrm{m}_{\mathrm{ASV}}
$$


In the range of open anti-surge valve, accurate knowledge of the air flow rate $\mathrm{m}_{2}$ allows to calculate quantities which depend on the flow rate.

In the subject-matter literature there are only a few publications concerning this range of gas turbine operation. The completion of the test stand by possible additional measurement of air flow extracted from anti-surge valve makes it possible to measure gas turbine basic parameters. The test stand in question is one of the full - scale gas turbine stands the best instrumented in measurement points in Poland.

\section{START - UP OF THE TURBINE SET}

During start- up and transition to idle work the turbine set operates with open anti-surge valve. The valve is controlled automatically by comparing the air pressure from behind the compressor with that reduced according to the scheme presented in the previous section. In the start-up initial phase the valve is open, but it is choked when the pressure $\mathrm{p}_{2}$ behind the compressor increases, Fig. 4. During start-up all the measured parameters become readjusted. The ASV is choked and opened again along with changes in the pressur $\mathrm{p}_{2}$.

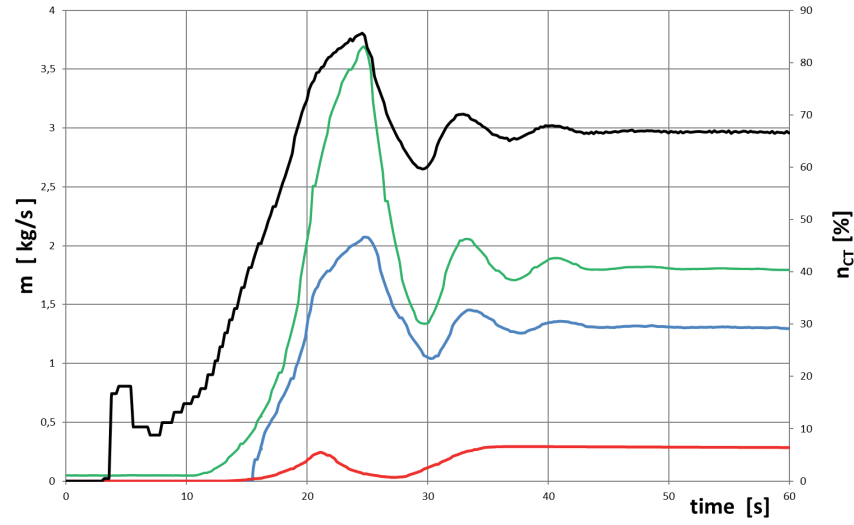

Fig. 4. Changes in the parameters of air flow rate at inlet to compressor, rotational speed of compressor turbine as well as air pressure at outlet from compressor and extraction-air flow rate during start-up of the turbine set

$$
-n_{C T}-p_{2}-m_{C} \longrightarrow m_{A S V}
$$

The start-up lasts about 30 seconds counting from the instant of switching-on the start-up apparatus till the transition to idle work. Character of changes in the air flow rate $m_{C}$, pressure $\mathrm{p}_{2}$ and compressor turbine rotational speed $\mathrm{n}_{\mathrm{CT}}$ is similar, Fig. 4 .

Fig. 5 shows time runs of air flow through the compressor during start-up. The air flow rate $\mathrm{m}_{2}$ delivered to the combustion chamber is equal to the air flow rate $\mathrm{m}_{\mathrm{C}}$ at inlet to the turbine set reduced by the extraction-air flow rate $\mathrm{m}_{\mathrm{ASV}}$. The ratio of extraction air flow rate and air flow rate at inlet, $\mathrm{m}_{\mathrm{ASV}} / \mathrm{m}_{\mathrm{C}}$, changes in time beginning from 0 up to 0,22 during idle work, Fg. 5.

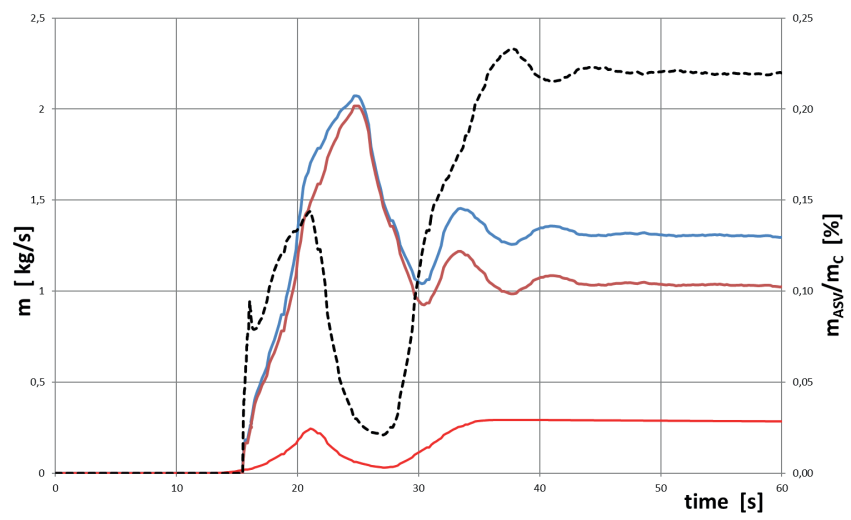

Fig. 5. Changes in air flow rates in the compressor during start-up $-m_{C}-m_{2} m_{A S V}--m_{A S V} / m_{C}$

During start-up, temperatures of air flow and gas flow in particular points of the cycle are changing, Fig. 6 . The gas flow temperatures : behind the combustion chamber, $t_{3}$, in passage between the turbines, $t_{3}$, at outlet from the power turbine, $\mathrm{t}_{4}$, have similar runs and repeat oscillations resulting from flowing gas, and their amplitudes become smaller along with increasing distance of measurement point from the combustion chamber. The smallest exhaust gas temperature oscillations occur behind the power turbine. Runs of air temperature behind the compressor, $t_{2}$, do not show such oscillations like those of gas flow.

Results of measurements of air temperature at outlet from the compressor, $t_{2}$, and extraction-air temperature $t_{A S V}$ during start-up are given in Fig. 7. During start-up the extraction-air temperature $t_{A S V}$ increases and its time run differs from that of the air behind the compressor, $\mathrm{t}_{2}$.

Fig. 8 presents changes in the rate of fuel flow delivered to the combustion chamber, $\mathrm{m}_{\mathrm{f}}$, on the background of the runs of the air flow rate $\mathrm{m}_{\mathrm{C}}$ and compressor turbine rotational speed $\mathrm{n}_{\mathrm{CT}}$. The fuel flow during start-up is limited because of fast increasing gas temperature behind the combustion chamber, to reach finally a value relevant to idle work, in the end of the start-up prcess.

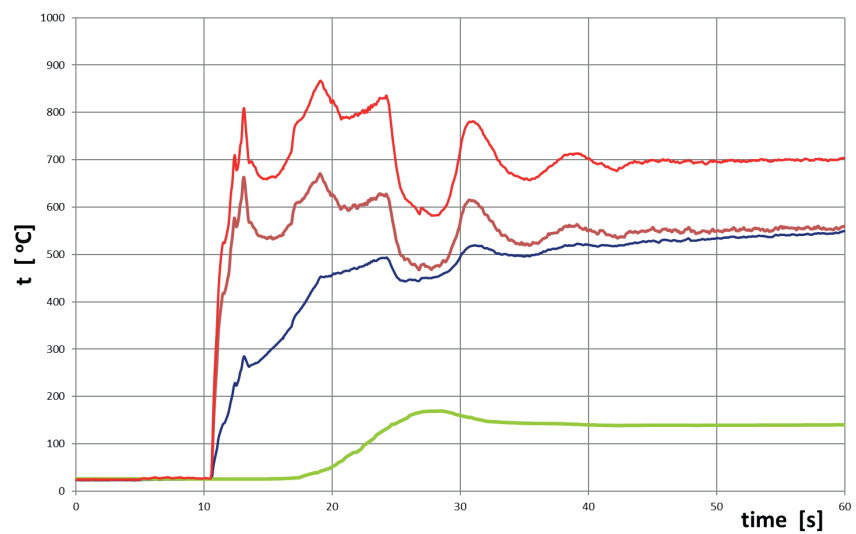

Fig. 6. Changes in air flow temperature and gas temperature in particular points of gas turbine cycle during start-up $t_{2} t_{3} \ldots t_{3}{ }_{3} t_{4}$ 


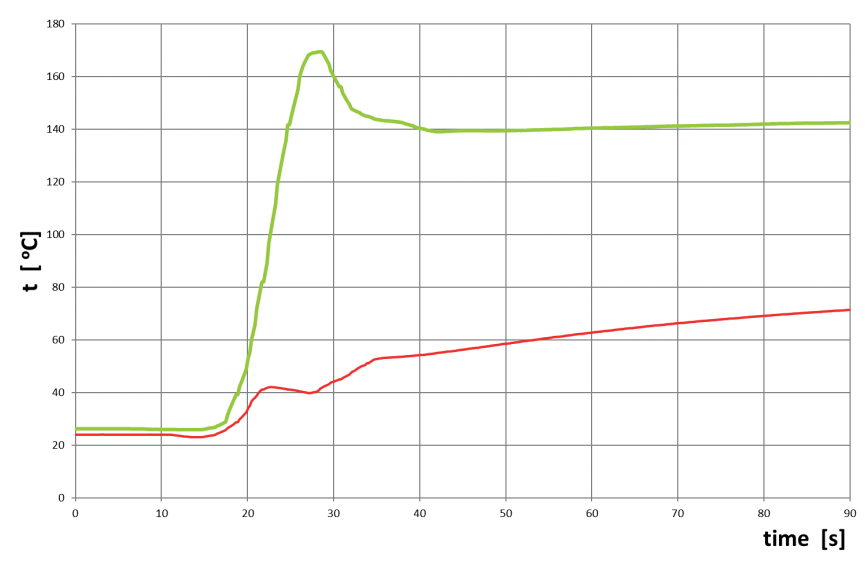

Fig. 7. Air temperature behind the compressor and in extraction valve during start-up $t_{A S V}-t_{2}$

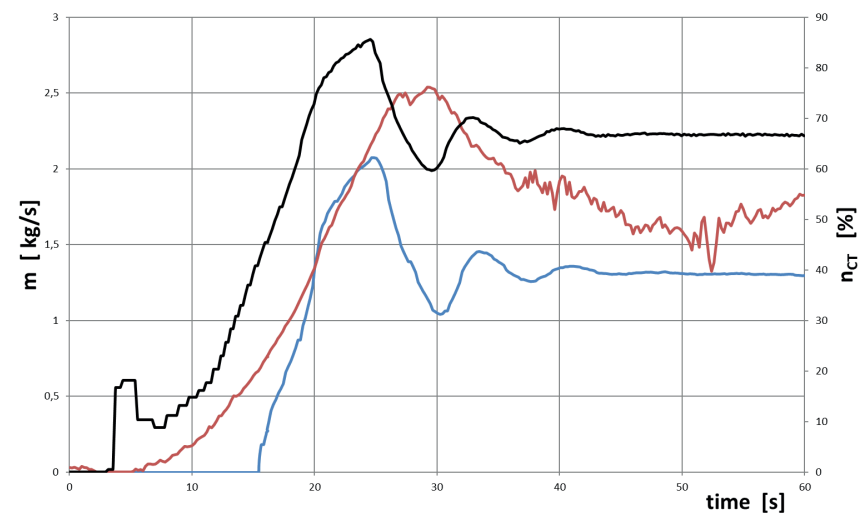

Fig. 8. Changes in the fuel flow rate and air flow rate at inlet to the compressor as well as in the rotational speed of the compressor turbine during start-up $n_{C T} m_{C} \longleftarrow m_{f} 100$

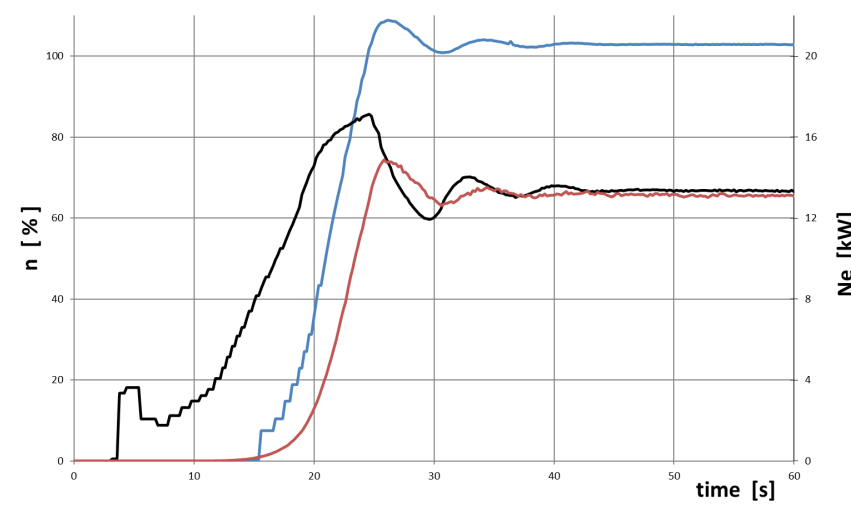

Fig. 9. Runs of the power output of the turbine set as well as of rotational speed of compressor turbine and power turbine during start-up $n_{C T} n_{P T} \longrightarrow \mathrm{Ne}$

Fig. 9 presents changes in the rotational speed of compressr turbine $\mathrm{n}_{\mathrm{CT}}$ and power turbine $\mathrm{n}_{\mathrm{PT}}$ as well as in the effective power of the turbine set, Ne. During start-up the eddy-current brake was preliminarily loaded by the power of about $13 \mathrm{~kW}$. Changes in the power $\mathrm{Ne}$ and the speed $\mathrm{n}_{\mathrm{PT}}$ in time have similar character.

\section{RANGE OF LOW LOADS OF THE TURBINE SET}

In the range of low loads of the turbine set the anti-surge valve is open. Along with increasing load of the turbine set, which is equivalent to increasing the rotational speed of the compressor turbine, the valve is being closed at the rotational speed $\mathrm{n}_{\mathrm{CT}}$ according to Fig. 2.1.

The experimental tests were conducted by loading the eddy-current brake step by step so as to shut the anti-surge valve up and then to make the valve to become open by unloading the turbine set.

Fig. 10 contains runs of the rotational speed of the compressor turbine, $\mathrm{n}_{\mathrm{CT}}$, and of the air pressure behind the compressor, $\mathrm{p}_{2}$ during shutting up and opening the anti-surge valve of the gas turbine. At the increasing of the speed $n_{\mathrm{CT}}$ up to about $79 \%$ the ASV starts shutting up, and its complete closure occurs at the speed of about $81 \%$. At further load increasing the turbine set operates in the range of closed anti-surge valve. During the loading, Fig.10, the ASV starts to open at the speed $\mathrm{n}_{\mathrm{CT}}$ equal to about $77,5 \%$ to be entirely open at the speed of about 7,5\%.

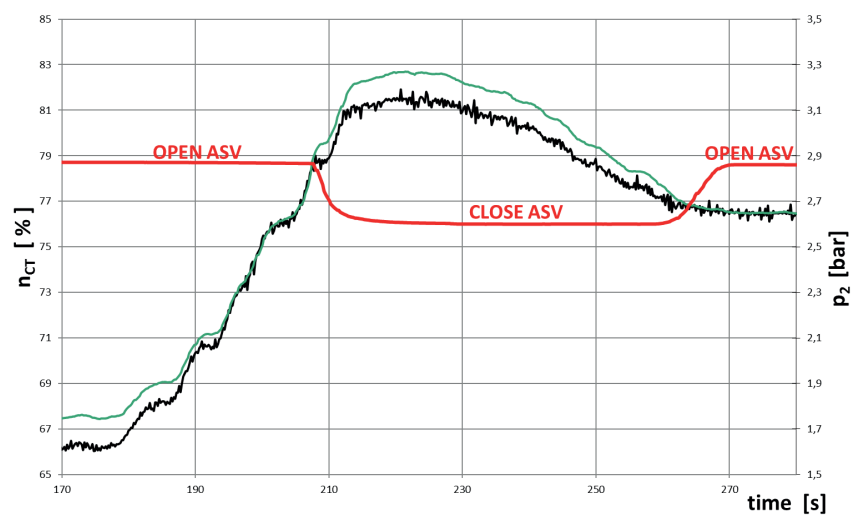

Fig. 10. Range of the turbine set's operation with closed and open anti-surge valve (ASV)

$$
-n_{C T}-p_{2} \_A S V
$$

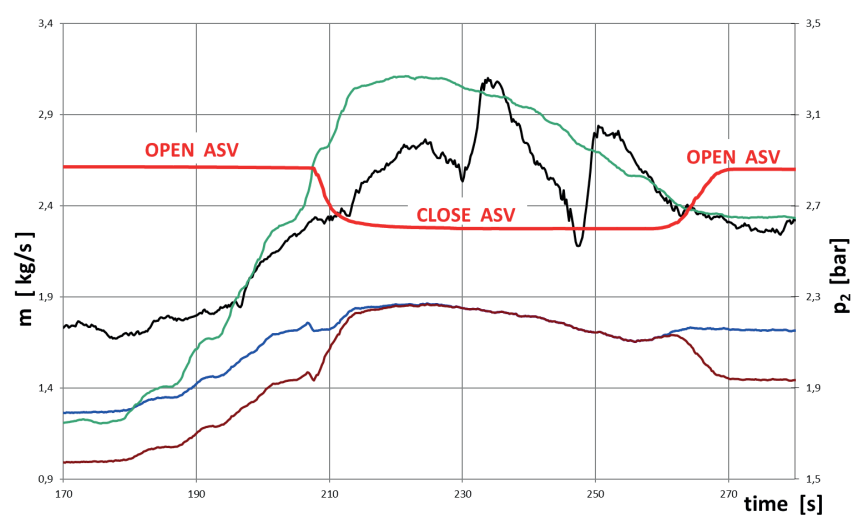

Fig. 11. Changes in air and fuel flow rates as well as the pressure $p_{2}$ in the range of closing and opening the ASV

$m_{C} \_p_{2} m_{f}^{*} 100 \_m_{2} \_$ASV 


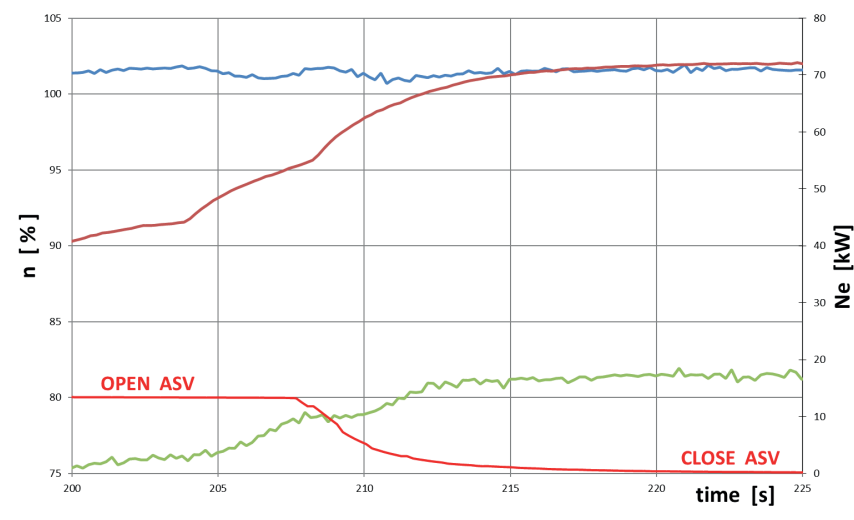

Fig. 12. Changes in gas turbine parameters in the range of closing the ASV $n_{C T} n_{P T} \_\mathrm{Ne} \_\mathrm{ASV}$

Fig. 11 presents changes in air flow through the compressor as well as in the pressure $\mathrm{p}_{2}$ and fuel flow during opening and closing the ASV. At the closed ASV the air flow rate $\mathrm{m}_{2}$ delivered to the combustion chamber is equal to the air flow rate at inlet to the compressor, $\mathrm{m}_{\mathrm{C}}$.

In the runs of changes in the power output $\mathrm{Ne}$ and the speed $\mathrm{n}_{\mathrm{CT}}$, changes associated with closing the ASV can be observed, however the speed $\mathrm{n}_{\mathrm{PT}}$ is not susceptible to closing or opening the ASV, Fig. 12.

The static characteristics of the gas turbine in the range of open ASV are presented in Fig. 13 and 14. The extraction-air flow rate $\mathrm{m}_{\mathrm{ASV}}$ is constant and amounts to $0,25 \mathrm{~kg} / \mathrm{s}$ in the range of open ASV. However during loading the turbine set, the ratio $\mathrm{m}_{\mathrm{ASV}} / \mathrm{m}_{\mathrm{C}}$ is varying because the air flow rate $\mathrm{m}_{\mathrm{C}}$ increases along with increasing the speed $\mathrm{n}_{\mathrm{CT}}$ (increasing power output of the gas turbine). The ratio drops begining from idle work till the start of ASV closing operation and varies between 0,22 and 0,15 . The temperature of the air mass flow $\mathrm{m}_{\mathrm{ASV}}$ rises a little from the value of $80^{\circ} \mathrm{C}$ to $85^{\circ} \mathrm{C}$ at closing the ASV. The temperature of the air behind the compressor, $\mathrm{t}_{2}$, in the same range of operation increases from about $145^{\circ} \mathrm{C}$ to $200^{\circ} \mathrm{C}$, and, the gas temperature behind the combustion chamber varies within the range from $700^{\circ} \mathrm{C}$ to about $20^{\circ} \mathrm{C}$.

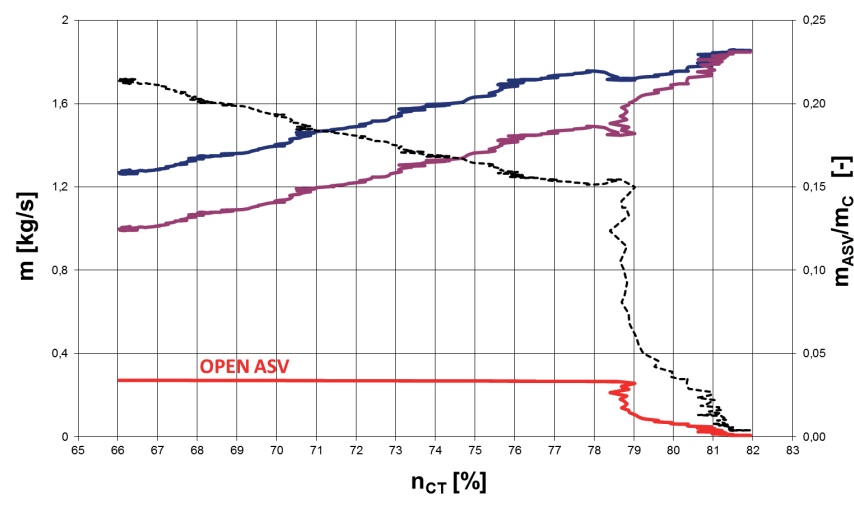

Fig. 13. Changes in air flow rates in function of changes in the speed $n_{C T}$ in the range of open ASV (the ASV starts to close at the speed $n_{C T}=79 \%$ )

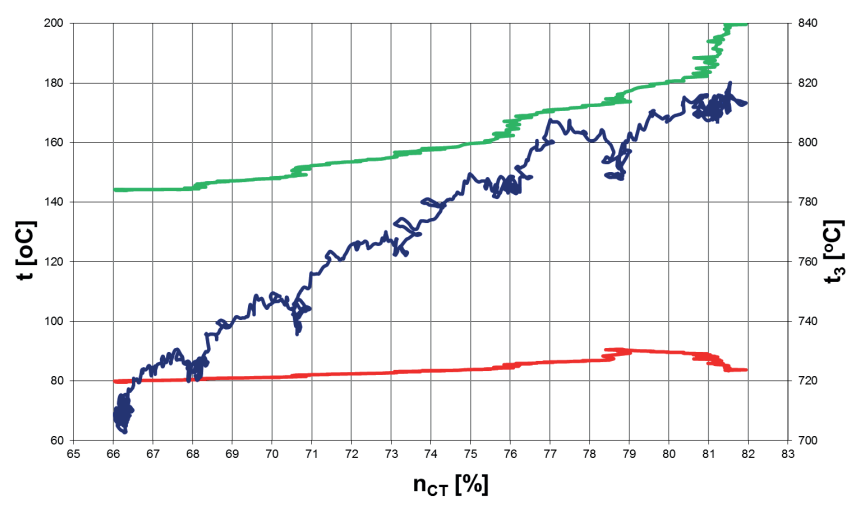

Fig. 14. Changes in exhaust air temperature in function of changes in the speed $n_{C T}$ in the range of open ASV (the ASV starts to close at the speed $\left.n_{C T}=a b t .79 \%\right)$

$$
t_{2} \longrightarrow t_{A S V} \longrightarrow t_{3}
$$

\section{CONCLUSIONS}

Experimental tests of gas turbine operation in the range of open anti-surge valve were performed. The tests covered two gas turbine operation ranges: the start-up range of the turbine set and the range of low loads on the gas turbine with open anti-surge valve.

The tests demonstrated that in start-up the range of the turbine set the gas turbine operates with open anti-surge valve. During start-up the ASV is chocked depending on a value of the air pressure behind the compressor as it results from the control process of the valve.

In the range of low loads on the turbine with open ASV the measurements make it possible to determine the air flow behind the compressor, delivered to the combustion chamber. Knowledge of amount of the flow allows to determine the gas turbine characteristics in the range of open anti-surge valve. And, in this range the extraction- air flow rate $\mathrm{m}_{\mathrm{ASV}}$ is constant irrespective of gas turbine loading.

\section{Designations}

$$
\begin{array}{ll}
\mathrm{m} & - \text { mass flow } \\
\mathrm{n} & \text { - shaft rotational speed } \\
\mathrm{Ne} & - \text { power of gas turbine } \\
\mathrm{p} & \text { - pressure } \\
\mathrm{t} & \text { - temperature }
\end{array}
$$

C - compressor

CC - combustion chamber

CT - compressor turbine

EB - eddy - current brake

PT - power turbine

ASV - anti-surge valve

\section{Cycle points}

$$
\begin{aligned}
& \text { - compressor inlet } \\
& \text { - compressor outlet } \\
& \text { - combustion chamber outlet } \\
& \text { - crossover between turbines } \\
& \text { - turbine outlet }
\end{aligned}
$$

Indexes

f - fuel

n - overpressure

p - negative pressure
4 - turbine outlet 
1. Dzida M. Frost J.: Two-shaft Gas Turbine Teaching and Testing Station. Journal of POLISH CIMEEAC, Vol. 11 No. 1 (2016) pp. 31-46

2. Dzida M.: Impact of changes in gas turbine main parameters on accuracy of calculation of upper temperature of gas turbine cycle ( in Polish). Zagadnienia Maszyn Przepływowych. Instytut Maszyn Przepływowych Polskiej Akademii Nauk, Gdańsk, 1993, pp.205-219.

3. Dzida M.: Possible Efficiency Increasing of Ship Propulsion and Marine Power Plant with the System Combined of Marine Diesel Engine, Gas Turbine and Steam Turbine. [Ed.] Ernesto Benini. Advances in Gas Turbine Technology. Rijeka : Published by InTech,, 2011, Chapter 3, pp. 45 -68.

4. Technical description of GTD-350 engine for Mi-2 helicopter ( in Polish). Document No.16.0.381. Issued on 3 May 1978. Wytwornia Sprzętu Komunikacyjnego „PZL Rzeszow".

5. Cortinovis A., Ferreaua H.J., Lewandowski D., Mercangöz M.: Experimental evaluation of MPC-based anti-surge and process control for electric driven centrifugal gas compressors. Journal of Process Control, 34 (2015), pp. $13-25$.

\section{Marek Dzida \\ Jacek Frost}

Faculty of Ocean Engineering and Ship Technology Gdansk University of Technology

Gabriela Narutowicza 11/12 80-233 Gdańsk

Poland 